\title{
VALIDATION OF SAND-MUD MIXTURE TRANSPORT MODEL WITH FIELD AND FLUME EXPERIMENTS
}

\author{
Taichi Kosako, Port and Airport Research Institute, kosako@pari.go.jp \\ Yasuyuki Nakagawa, Kyushu University, y.nakagawa@civil.kyushu-u.ac.jp \\ Takashi Umeyama, Ministry of Land, Infrastructure, Transport and Tourism, umeyama-t8910@qsr.mlit.go.jp \\ Masaru Takayama, Ministry of Land, Infrastructure, Transport and Tourism, takayama-m899v@mlit.go.jp
}

\begin{abstract}
INTRODUCTION
In coastal and estuarine environments, sand-mud mixtures are often formed due to supply of various types of sediment discharge from rivers. For better prediction of the sediment transport patterns and the resultant bathymetry changes in these areas, it is important to apply a sediment transport model that can represent the behavior of sand-mud mixtures depending on the mud content to the simulation.

This study aims at elucidating the effect of the mud content on the erosion processes of sand-mud mixtures under the combined wave and current forces through a field observation and flume experiments. A sand-mud mixture transport model was validated based on the field and experimental results.
\end{abstract}

\section{FIELD OBSERVATION}

The field monitoring was conducted for almost 2 weeks from Aug. 18 through Sept. 2 in 2016 to measure current velocities, wave height, tide level, suspended sediment concentration and particle size distribution of suspended sediments at 4 points around the Kumamoto Port, which is located in the south-eastern shore of the Ariake Bay, Japan (Fig.1). Core samples were also taken at each site and analyzed to identify bed properties. Through analysis of monitoring data and core samples, it is found that the mud content is an important role in the concentrations and the particle size distributions of suspended sediments, or the erodibility of sand-mud mixtures.

\section{FLUME EXPERIMENT}

Several experiments on the transport processes of sandmud mixtures were carried out with the 2-D circulating flume (Fig.2). The sediment samples with varying mud content (3.9 to $82.7 \%$ ), which were formed with the sediments in the field, were set in the flume. In the experiments, two types of flow conditions (an only unidirectional flow or combined oscillatory and unidirectional flows) were also forced against each sample. The dependency of the sediment erodibility on the mud content were quantitatively evaluated on a basis of sediments transported mainly as bed load and settled in the sediment traps, and bottom level changes under each flow conditions. The experimental results indicate that the bed load transport (critical shear stress) largely decreases (increases) with increasing mud content (Fig.3).

\section{NUMERICAL SIMULATION}

A sand-mud mixture transport model is based on the idea of Van Ledden (2003), which implements a transition between the non-cohesive (sand) and cohesive (mud) behaviors dependent on mud content. The sediment transport processes in the flume experiments were simulated with the present model. The simulated results show a good agreement with the experimental ones, quantitatively reproducing the relationship between the transport rate and the force condition or the mud content (Fig.3). A sediment transport simulation around the Kumamoto Port was then carried out by using the sandmud mixture transport model parameterized with the experimental results, and reproducibility and problems in the future of the present model will be finally discussed.

\section{SUMMARY}

Through data analysis of the field measurement and the flume experiments, we examined the transport processes of sand-mud mixtures under waves and tidal currents. We also simulated the transport processes of sand-mud mixtures and discussed reproducibility of the simulated results by comparison with the field and experimental results.

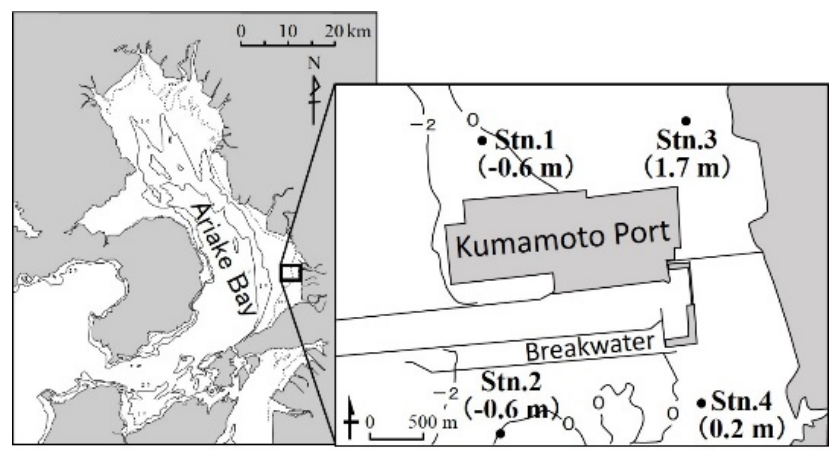

Figure 1 - Monitoring sites around the Kumamoto Port (right), where is located southeast of the Ariake Bay (left).

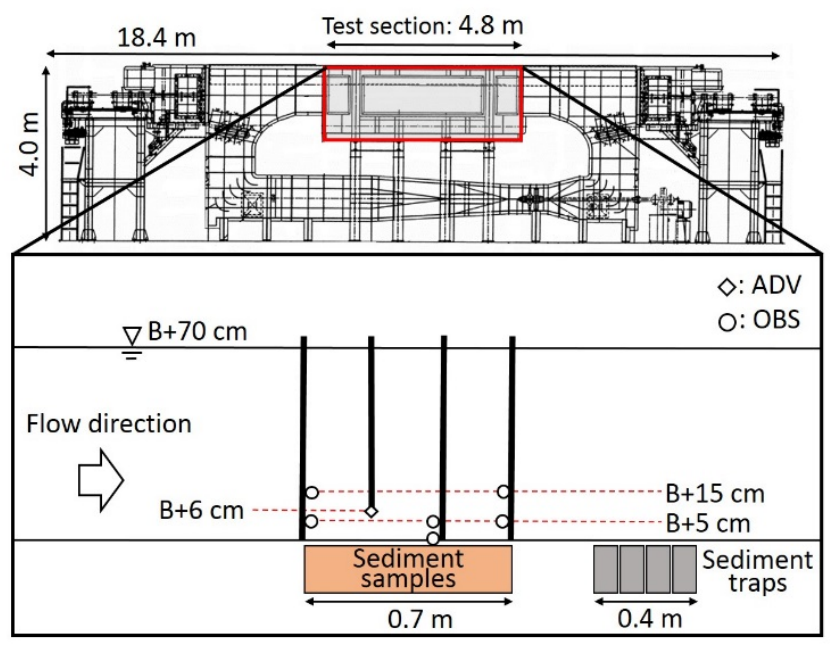

Figure 2 - Instrumentation layout in the flume. 

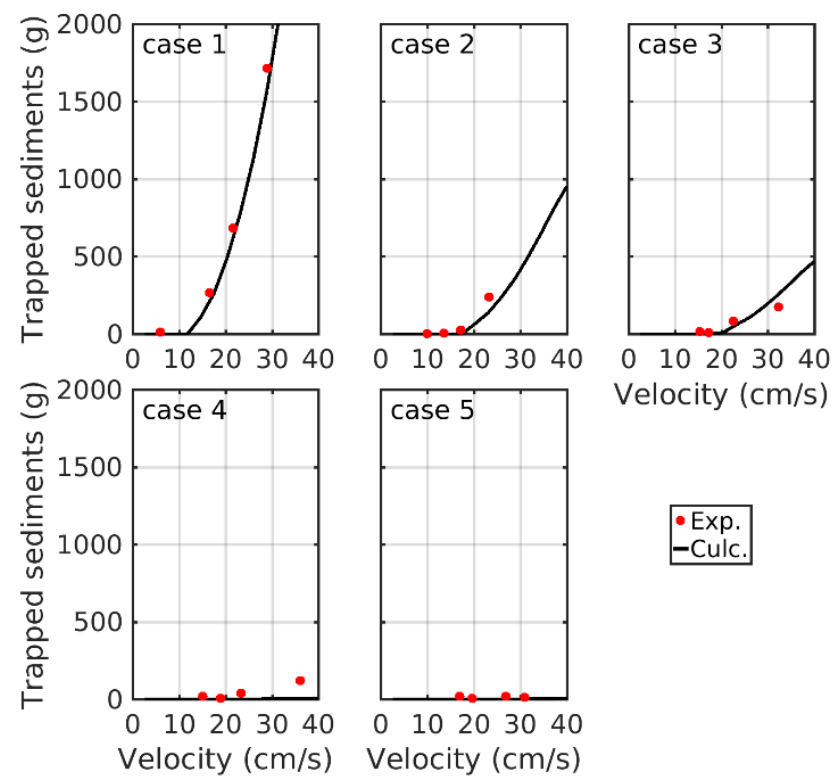

-Exp.

-Culc.

Figure 3 - Trapped sediments mainly due to bed load transport in the flume experiment (red dot) and the numerical simulation (black line) under unidirectional flow conditions.

\section{REFERENCES}

Van Ledden M. (2003): Sand-mud segregation in estuaries and tidal basins, PhD-thesis, Delft University of Civil Engineering, Report No.03-2, ISSN0169-6548. 